\title{
Cost of Glycemic Target Achievement with Sodium Glucose Co-transporter 2 Inhibitors in Patients with Type 2 Diabetes in the UK
}

\author{
Marc Evans (D) Sayeed Achha · Cheryl Neslusan
}

Received: July 19, 2017 / Published online: September 25, 2017

(c) The Author(s) 2017. This article is an open access publication

\begin{abstract}
Introduction: Diabetes-related costs make up a large portion of healthcare expenditures in the UK. Many of these costs are related to treatment of diabetes-related complications. Reducing HbA1c to $<7.0 \%(53 \mathrm{mmol} / \mathrm{mol})$ reduces the incidence of complications and comorbidities. Metformin plus sulfonylurea is the most common dual oral combination therapy in the UK. The costs of achieving HbA1c $<7.0 \%$ in patients inadequately controlled on metformin plus sulfonylurea were analyzed for the sodium glucose co-transporter 2 (SGLT2) inhibitors canagliflozin, dapagliflozin, and empagliflozin from the perspective of the UK National Health System.

Methods: A Bayesian network meta-analysis (NMA) was used to compare the proportion of patients with type 2 diabetes mellitus inadequately controlled on metformin plus
\end{abstract}

Enhanced content To view enhanced content for this article go to http://www.medengine.com/Redeem/ 9A4CF06072EC16A6.

M. Evans ( $\square)$

Diabetes Resource Centre, University Hospital

Llandough, Cardiff, UK

e-mail: marclyndon1@hotmail.com

S. Achha

Janssen UK, High Wycombe, UK

C. Neslusan

Janssen Global Services, LLC, Raritan, NJ, USA sulfonylurea that achieved HbA1c $<7.0 \%$ after 26 weeks with canagliflozin 100 and $300 \mathrm{mg}$, dapagliflozin $10 \mathrm{mg}$, and empagliflozin 10 and $25 \mathrm{mg}$; odds ratios (ORs) and pairwise probabilities $(P)$ for canagliflozin versus dapagliflozin and empagliflozin were calculated. The costs associated with achieving HbA1c $<7.0 \%$ were estimated on the basis of medication costs and the proportion of patients achieving the HbA1c goal.

Results: NMA results showed that a higher proportion of patients treated with canagliflozin $300 \mathrm{mg}$ achieved HbA1c $<7.0 \%$ (41\%) compared with those treated with dapagliflozin $10 \mathrm{mg}$ (25\%), empagliflozin $10 \mathrm{mg}$ (23\%), empagliflozin $25 \mathrm{mg}(28 \%)$, or canagliflozin $100 \mathrm{mg}$ (27\%). The odds of achieving HbA1c $<7.0 \%$ were greater with canagliflozin $300 \mathrm{mg}$ than with dapagliflozin $10 \mathrm{mg}$ (OR 2.03 $[P=94 \%]$ ), empagliflozin $10 \mathrm{mg}$ (OR 2.29 $[P=99 \%])$, or empagliflozin $25 \mathrm{mg}$ (OR 1.71 $[P=93 \%])$. The per patient costs of achieving $\mathrm{HbA} 1 \mathrm{c}<7.0 \%$ at 26 weeks were $£ 881, £ 580$, $£ 951, £ 1034$, and $£ 849$ with canagliflozin 100 and $300 \mathrm{mg}$, dapagliflozin $10 \mathrm{mg}$, and empagliflozin 10 and $25 \mathrm{mg}$.

Conclusions: This analysis suggests that, in the UK, canagliflozin $300 \mathrm{mg}$ provides the best value for money among all SGLT2 inhibitors in terms of achieving $\mathrm{HbA} 1 \mathrm{c}<7.0 \%$ when used as part of triple therapy with metformin plus sulfonylurea. 
Funding: Janssen Global Services, LLC, Raritan, NJ, USA.

Keywords: Canagliflozin; Cost to treat; Dapagliflozin; Empagliflozin; SGLT2 inhibitor; Type 2 diabetes mellitus; United Kingdom

\section{INTRODUCTION}

Approximately 3.5 million people living in the UK have been diagnosed with diabetes. Currently, annual indirect and direct costs associated with diabetes are estimated to be $£ 23.7$ billion, which constitutes around $10 \%$ of the National Health Service (NHS) budget [1, 2]. As the prevalence of type 2 diabetes mellitus (T2DM) is projected to increase in the coming years, the disease will pose an even greater economic and healthcare burden. By 2035/2036, the total cost associated with diabetes in the UK is projected to rise to $£ 39.8$ billion [1].

Currently, the cost of prescription medication makes up only a small proportion of total spending on diabetes, about $£ 803$ million, with the majority of T2DM costs $(\geq 80 \%)$ attributable to the management of diabetesrelated micro- and macrovascular complications $[1,3]$. If funding and efficiency rates remain the same, the overall increased demand for healthcare will create a $£ 30$ billion shortfall in the NHS budget by 2020/2021 [4]. Prevention of diabetes-related complications is essential to controlling healthcare costs and helping to close this budget gap.

The NHS plan for the future, the Five Year Forward View (FYFV), is based on achieving the triple aim of improving the health of the entire population and providing better-quality patient care, while at the same time providing better value for taxpayers within a financially sustainable healthcare system [4,5]. Through the NHS Right Care program, the FYFV also aims to reduce the variation in quality, safety, and health outcomes while optimizing the allocation of resources across the healthcare system [6]. As part of achieving these aims, the FYFV emphasizes the need for preventative care. For patients with T2DM, serious complications can be postponed or even avoided completely with relatively small investments in preventative care, providing a huge payback to the individual, their family, the community, and the NHS.

An important component of preventative care for patients with T2DM is achieving and maintaining glycemic control. Glycemic control is the cornerstone of T2DM management, with a target of $\mathrm{HbA} 1 \mathrm{c} \leq 7.0 \%(53 \mathrm{mmol} / \mathrm{mol})$ recommended for most patients by the National Institute for Health and Care Excellence (NICE) in the UK [7]. Maintaining HbA1c $<7.0 \%$ has been shown to reduce the risk of T2DM-related complications and may lead to significant cost savings $[8,9]$. Although metformin is the standard first-line therapy, many patients with T2DM require combination therapy with multiple antihyperglycemic agents (AHAs) to achieve glycemic control. Metformin plus sulfonylurea is the most common oral dualtherapy combination in the UK. However, many patients fail to achieve glycemic targets on existing treatments, including metformin plus sulfonylurea [10].

Sodium glucose co-transporter 2 (SGLT2) inhibitors lower blood glucose by increasing urinary glucose excretion, which leads to a mild osmotic diuresis and a net caloric loss [11, 12]. Three SGLT2 inhibitors are approved for the treatment of T2DM in the UK-canagliflozin, dapagliflozin, and empagliflozin. In clinical trials, canagliflozin 100 and $300 \mathrm{mg}$, dapagliflozin $10 \mathrm{mg}$, and empagliflozin 10 and $25 \mathrm{mg}$ improved glycemic control, reduced body weight, and reduced blood pressure in patients with T2DM in a range of studies, including as add-on to metformin plus sulfonylurea [13-18].

While there have not been any head-to-head clinical trials of SGLT2 inhibitors in patients with T2DM, indirect comparisons suggest that canagliflozin $300 \mathrm{mg}$ has the greatest HbA1c-lowering efficacy $[19,20]$, which may impact long-term health outcomes and costs. NICE guidelines specify an HbA1c goal of $\leq 7.0 \%$ for most patients [7]. The purpose of this study was to compare the cost of achieving HbA1c $<7.0 \%$ with canagliflozin, dapagliflozin, and empagliflozin in patients with T2DM inadequately controlled with metformin plus sulfonylurea from the perspective of the NHS using a network meta-analysis (NMA). 


\section{METHODS}

\section{Network Meta-Analysis}

Relative effects between SGLT2 inhibitors for the proportion of patients achieving HbA1c $<7.0 \%$ were estimated by performing a Bayesian NMA on a study population consisting of patients who participated in placebo- or active-controlled clinical trials reporting data greater with canagliflozin 100 or $300 \mathrm{mg}$ versus the alternative.

\section{Cost Analysis}

The per patient cost associated with achieving $\mathrm{HbA} 1 \mathrm{c}<7.0 \%$ at 26 weeks was calculated in Microsoft Excel using the following equation:

Cost of achieving HbA1c $<7.0 \%=\frac{\text { Drug cost for } 26 \text { weeks of treatment }}{\text { Proportion of patients achieving HbA1c }<7.0 \% \text { at } 26 \text { weeks }}$

for triple therapy with metformin plus sulfonylurea in adults with inadequately controlled T2DM [21]. Achievement of HbA1c $<7.0 \%$ was chosen for this analysis because it was the most commonly reported target in the publications of clinical trials included in the network of evidence. This target has been used in other Bayesian NMAs evaluating the relative efficacy of SGLT2 inhibitors [20, 21].

The NMA was based on a systematic literature review (SLR) at $26 \pm 4$ weeks and was conducted in line with NICE guidelines $[22,23]$. The outcome of interest was the proportion of patients reaching the target of HbA1c $<7.0 \%$. The selection of fixed versus random effects was based on the deviance information criterion (DIC), which measures the relative goodness of fit between models [24]. Networks had treatment- and dose-specific nodes for all AHA classes, but only results for SGLT2 inhibitors were used in this analysis. Odds ratios (ORs) for comparisons of canagliflozin 100 and $300 \mathrm{mg}$ versus empagliflozin 10 and $25 \mathrm{mg}$ and dapagliflozin $10 \mathrm{mg}$ were estimated. Additionally, Bayesian pairwise probabilities $(P)$ of canagliflozin 100 and $300 \mathrm{mg}$ versus empagliflozin 10 and $25 \mathrm{mg}$ and dapagliflozin $10 \mathrm{mg}$ were calculated, reflecting the likelihood that canagliflozin performed better than the comparator. $P>50 \%$ indicates an increased likelihood that the proportion achieving $\mathrm{HbA} 1 \mathrm{c}<7.0 \%$ is
The total drug acquisition cost for each SGLT2 inhibitor was calculated as the list price per unit dose (the daily cost of all three SGLT2 inhibitors marketed in the UK is the same, $\sim £ 1.31)$ multiplied by the number of doses received over 26 weeks ( 182 doses; total of $£ 238$ each, since each agent is a once-daily drug). The costs of background treatments were not considered and were assumed to be the same for all analyzed treatments given the similarity among the trial designs. The proportion of patients achieving HbA1c $<7.0 \%$ at 26 weeks with each treatment was reported in the primary publications [13-16].

\section{Compliance with Ethics Guidelines}

This article is based on previously conducted studies and does not involve any new studies of human or animal subjects performed by any of the authors.

\section{RESULTS}

\section{NMA Results}

The SLR identified 16 trials that reported the proportion of patients who reached the HbA1c target of $<7.0 \%$ at $26 \pm 4$ weeks of treatment as add-on to metformin plus sulfonylurea (Fig. 1). Only studies of SGLT2 inhibitors were included 


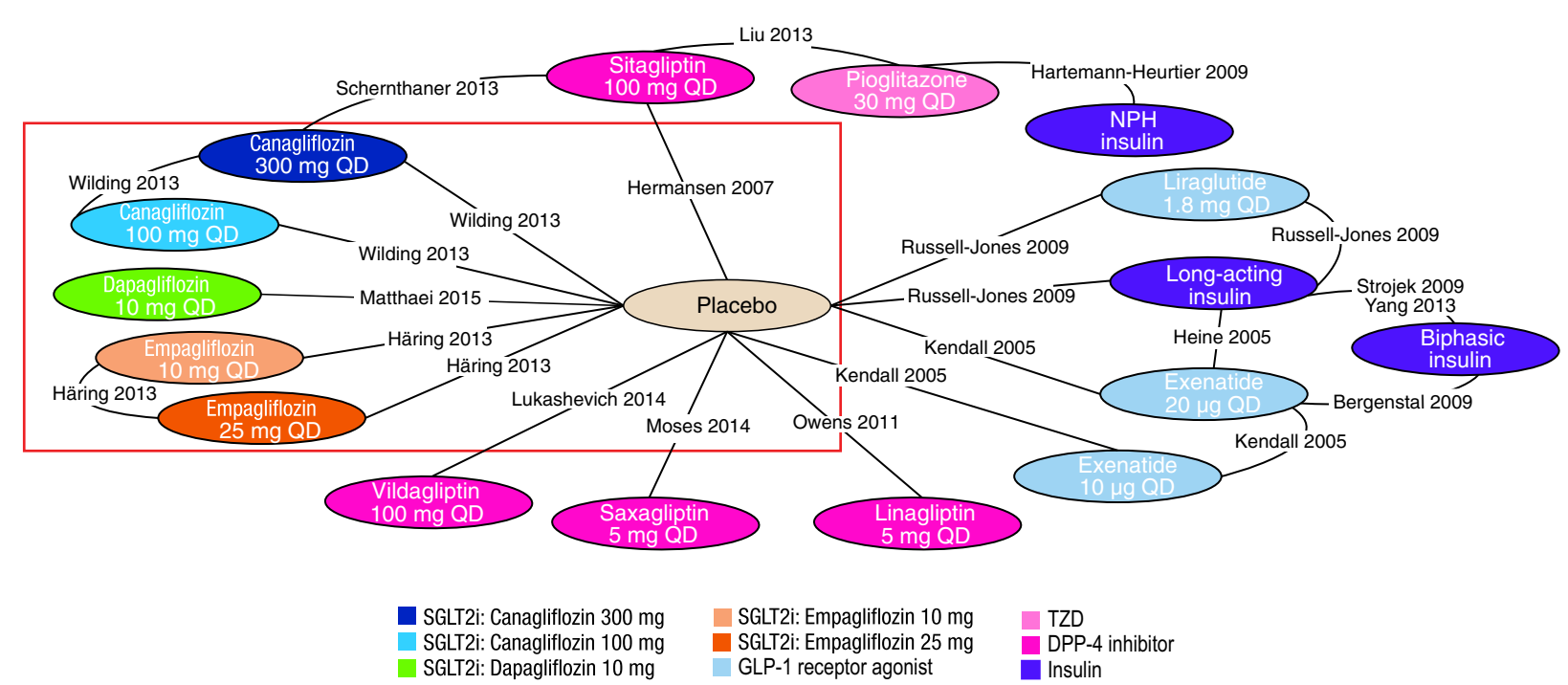

Fig. 1 Network of evidence included in this analysis [13-16, 45-55]. SGLT2i sodium glucose co-transporter 2 inhibitor, TZD thiazolidinedione, DPP-4 dipeptidyl

in this analysis. Two trials assessed canagliflozin 100 and $300 \mathrm{mg}$ (one trial was placebo controlled and one was versus sitagliptin $100 \mathrm{mg}$ ) $[13,14]$. One trial assessed dapagliflozin $10 \mathrm{mg}$ versus placebo [15], and one trial assessed empagliflozin 10 and $25 \mathrm{mg}$ versus placebo [16].

Baseline demographics were generally similar across the studies (Table 1). Mean baseline HbA1c was $8.1 \%(65 \mathrm{mmol} / \mathrm{mol})$ in the canagliflozin studies, $8.1-8.2 \%(65-66 \mathrm{mmol} / \mathrm{mol})$ in the dapagliflozin study, and $8.1-8.2 \%$ $(65-66 \mathrm{mmol} / \mathrm{mol})$ in the empagliflozin study [13-16]. NMA results showed that $41 \%$ of patients achieved HbA1c $<7.0 \%$ over 26 weeks with canagliflozin $300 \mathrm{mg}$ as add-on to metformin plus sulfonylurea compared with $27 \%$, $25 \%, 23 \%$, and $28 \%$ with canagliflozin $100 \mathrm{mg}$, dapagliflozin $10 \mathrm{mg}$, and empagliflozin 10 and $25 \mathrm{mg}$, respectively (Fig. 2). Patients treated with canagliflozin $300 \mathrm{mg}$ had higher odds of achieving HbA1c $<7.0 \%$ compared with dapagliflozin $10 \mathrm{mg}$ (OR $2.03[P=94 \%])$, empagliflozin $10 \mathrm{mg}$ (OR $2.29 \quad[P=99 \%])$, and empagliflozin $25 \mathrm{mg}$ (OR 1.71 [P=93\%]; Fig. 3). Patients treated with canagliflozin $100 \mathrm{mg}$ had fairly similar odds of achieving HbA1c $<7.0 \%$ compared with dapagliflozin $10 \mathrm{mg}$ (OR 1.12 $[P=60 \%])$ and empagliflozin $25 \mathrm{mg}$ (OR 0.94 peptidase-4, GLP-1 glucagon-like peptide-1, QD once daily, $\mathrm{NPH}$ neutral protamine Hagedorn. The studies of SGLT2 inhibitors included in this analysis are surrounded by a box

$[P=44 \%])$ and higher odds versus empagliflozin $10 \mathrm{mg}$ (OR $1.26[P=73 \%])$.

\section{Cost of Achieving Glycemic Control}

The costs of achieving HbA1c $<7.0 \%$ were $£ 881$, $£ 580, £ 951, £ 1034$, and $£ 849$ with canagliflozin 100 and $300 \mathrm{mg}$, dapagliflozin $10 \mathrm{mg}$, and empagliflozin 10 and $25 \mathrm{mg}$, respectively, as add-on to metformin plus sulfonylurea (Fig. 4). The cost was lowest with canagliflozin $300 \mathrm{mg}$ owing to the larger percentage of patients achieving HbA1c $<7.0 \%$.

\section{DISCUSSION}

The results from a Bayesian NMA of trials of SGLT2 inhibitors as add-on to metformin plus sulfonylurea for patients with T2DM inadequately controlled with metformin plus sulfonylurea showed that canagliflozin $300 \mathrm{mg}$ was more likely to provide HbA1c $<7.0 \%$ compared with other SGLT2 inhibitors. These results are consistent with other indirect comparisons of SGLT2 inhibitors from Bayesian and frequentist NMAs, which found that canagliflozin $300 \mathrm{mg}$ provides greater reductions in HbA1c compared 
Table 1 Baseline characteristics across studies of SGLT2 inhibitors

\begin{tabular}{|c|c|c|c|c|}
\hline \multirow[t]{2}{*}{ Parameter } & \multicolumn{2}{|l|}{ Canagliflozin } & \multirow{2}{*}{$\begin{array}{l}\text { Dapagliflozin } \\
\text { Matthaei et al. } \\
{[15]}\end{array}$} & \multirow{2}{*}{$\begin{array}{l}\text { Empagliflozin } \\
\text { Häring et al. } \\
{[16]}\end{array}$} \\
\hline & $\begin{array}{l}\text { Wilding et al. } \\
{[13]}\end{array}$ & $\begin{array}{l}\text { Schernthaner et al. } \\
{[14]}\end{array}$ & & \\
\hline Patients, $n$ & 469 & 755 & 216 & 666 \\
\hline Age $^{\mathrm{a}}$, years & $56.1-57.4$ & $56.6-56.7$ & $60.9-61.1$ & $56.9-57.4$ \\
\hline $\begin{array}{l}\text { HbAlc inclusion } \\
\text { criteria, } \% \\
(\mathrm{mmol} / \mathrm{mol})\end{array}$ & $7.0-10.5(53-91)$ & $7.0-10.5(53-91)$ & $7.0-10.5(53-91)$ & $7.0-10.0(53-86)$ \\
\hline $\begin{array}{l}\mathrm{HbAlc}^{\mathrm{a}}, \% \\
\quad(\mathrm{mmol} / \mathrm{mol})\end{array}$ & $8.1(65)$ & $8.1(65)$ & $8.1-8.2(65-66)$ & $8.1-8.2(65-66)$ \\
\hline Body weight $^{\mathrm{a}}, \mathrm{kg}$ & $91.2-93.8$ & $87.4-89.1$ & $88.6-90.1$ & $76.2-77.5$ \\
\hline $\mathrm{BMI}^{\mathrm{a}}, \mathrm{kg} / \mathrm{m}^{2}$ & $32.7-33.3$ & $31.5-31.7$ & $31.9-32.0$ & $27.9-28.3$ \\
\hline $\begin{array}{l}\text { Duration of } \\
\text { T2DM }^{\mathrm{a}} \text {, years }\end{array}$ & $9.0-10.3$ & $9.4-9.7$ & $9.3-9.6$ & NR \\
\hline $\begin{array}{l}\text { Metformin } \\
\text { inclusion criteria }\end{array}$ & $\begin{array}{l}\geq 2000 \text { or } \\
\geq 1500 \mathrm{mg} / \text { day if } \\
\text { unable to tolerate } \\
\text { a higher dose }\end{array}$ & $\begin{array}{l}\geq 2000 \text { or } \\
\geq 1500 \mathrm{mg} / \text { day if } \\
\text { unable to tolerate } \\
\text { a higher dose }\end{array}$ & $\geq 1500 \mathrm{mg} /$ day & $\begin{array}{l}\geq 1500 \mathrm{mg} / \text { day or maximum } \\
\text { tolerated or maximum according } \\
\text { to local label }\end{array}$ \\
\hline $\begin{array}{l}\text { Sulfonylurea } \\
\text { inclusion criteria }\end{array}$ & $\begin{aligned} \geq & \text { Half maximal } \\
& \text { labeled dose }\end{aligned}$ & $\begin{aligned} \geq & \text { Half maximal } \\
& \text { labeled dose }\end{aligned}$ & $\begin{array}{l}\text { Maximum } \\
\text { tolerated dose } \\
(\geq \text { half } \\
\text { maximal } \\
\text { labeled dose) }\end{array}$ & $\begin{array}{l}\geq \text { Half of the maximum } \\
\text { recommended dose, or maximum } \\
\text { tolerated dose, or maximum } \\
\text { according to local label }\end{array}$ \\
\hline $\begin{array}{l}\text { Stable dose of } \\
\text { metformin and } \\
\text { sulfonylurea } \\
\text { inclusion criteria }\end{array}$ & $\geq 8$ weeks & $\geq 8$ weeks & $\geq 8$ weeks & $\geq 12$ weeks \\
\hline
\end{tabular}

SGLT2 sodium glucose co-transporter 2, BMI body mass index, T2DM type 2 diabetes mellitus, NR not reported

a Data are mean baseline values across treatment arms for each study

with dapagliflozin $10 \mathrm{mg}$ and empagliflozin $25 \mathrm{mg}$ and helps a greater proportion of patients achieve HbA1c $<7.0 \%$ compared with dapagliflozin $10 \mathrm{mg}[19,20]$. These previous studies also showed that canagliflozin $300 \mathrm{mg}$ as monotherapy or in combination with metformin reduced fasting plasma glucose and systolic blood pressure to a greater extent than other SGLT2 inhibitors $[19,20]$. Taken together, these results suggest that canagliflozin $300 \mathrm{mg}$ may have greater glycemic efficacy than other SGLT2 inhibitors.

In the current analysis of patients with T2DM and suboptimal glycemic control on metformin plus sulfonylurea, initiation of canagliflozin at the recommended starting dose of $100 \mathrm{mg}$ provides a lower cost of achieving HbA1c $<7.0 \%$ than initiation of dapagliflozin $10 \mathrm{mg}$ or empagliflozin $10 \mathrm{mg}$ (recommended starting dose). For patients who do not achieve 


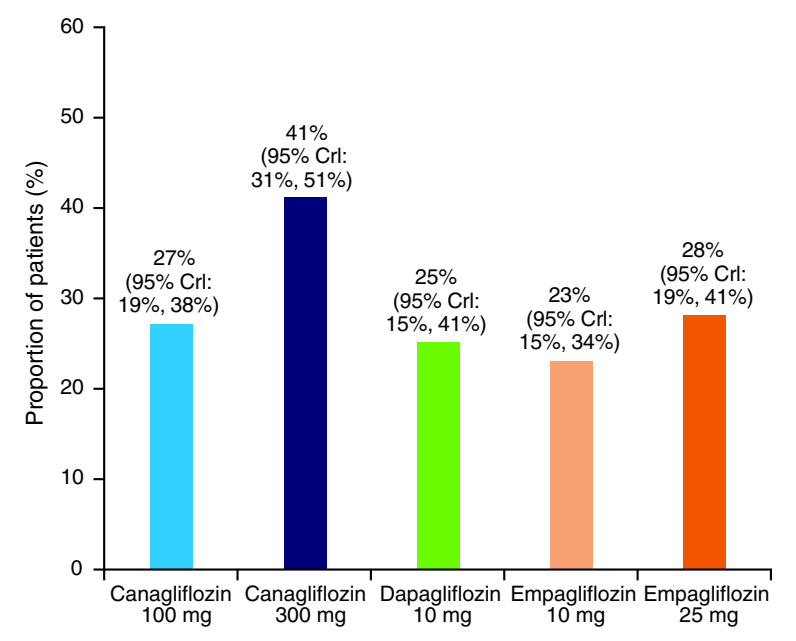

Fig. 2 Proportion of patients achieving HbAlc $<7.0 \%$ at 26 weeks. CrI credible interval

adequate glycemic control with lower doses of SGLT2 inhibitors and can tolerate the increase, the dose of SGLT2 inhibitor will be increased to $300 \mathrm{mg}$ for canagliflozin or $25 \mathrm{mg}$ for empagliflozin. Of all the doses of SGLT2 inhibitors compared in this study, the cost of achieving HbA1c $<7.0 \%$ over 26 weeks was lowest for canagliflozin $300 \mathrm{mg}$.

Analysis of cost per response is a simple and transparent way to compare the actual versus daily acquisition drug costs per patient [25]. This straightforward analysis may be easier to understand and more meaningful to physicians and payers than conventional cost-effectiveness analyses that report quality-adjusted life years (QALYs). An analysis similar to the current study was performed on the basis of the outcome of cost per $1 \%$ reduction in $\mathrm{HbA1c}$ for canagliflozin, dapagliflozin, and empagliflozin, which was intended to serve as a preliminary report demonstrating to US formulary committees that cost per response may be a valuable measure to include in decision-making related to inclusion of SGLT2 inhibitors [25]. Notably, that study used data from the studies reported in each drug's US Food and Drug Administration (FDA)-approved prescribing information and did not allow for statistical comparisons between the different SGLT2 inhibitors, which were possible in the current study owing to the use of the NMA as the data source.

This kind of cost per response analysis can also help guide policies aimed at reducing variation in quality of care and be used to inform local and national guideline development. Across the UK, the percentage of patients achieving glycemic control (HbA1c $\leq 7.5 \%$ [59 $\mathrm{mmol} / \mathrm{mol}]$ ) varies from $65.4 \%$ in Northern

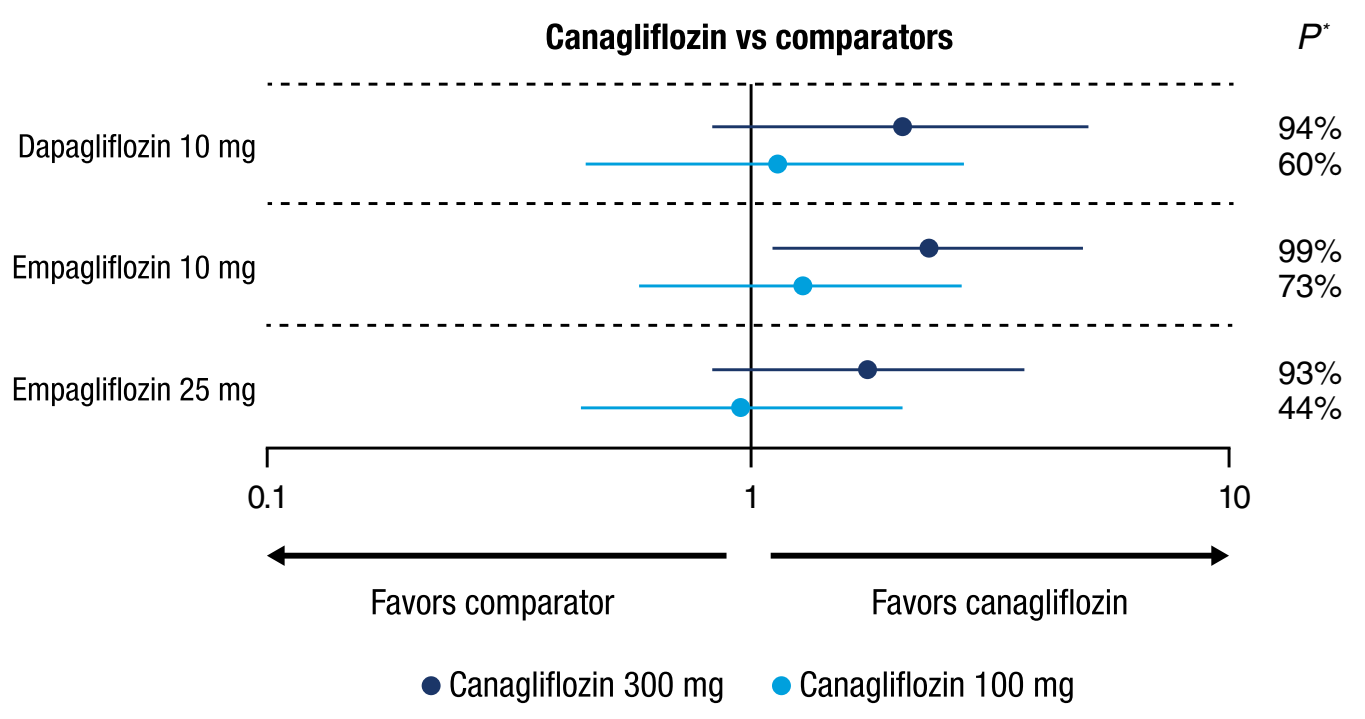

Fig. 3 OR (95\% CrI) for achieving HbAlc $<7.0 \%$ with canagliflozin 100 and $300 \mathrm{mg}$ versus comparators. CANA canagliflozin, DAPA dapagliflozin, EMPA empagliflozin,
OR odds ratio, CrI credible interval. ${ }^{*} P=$ Bayesian probability for CANA to be more effective versus comparator 


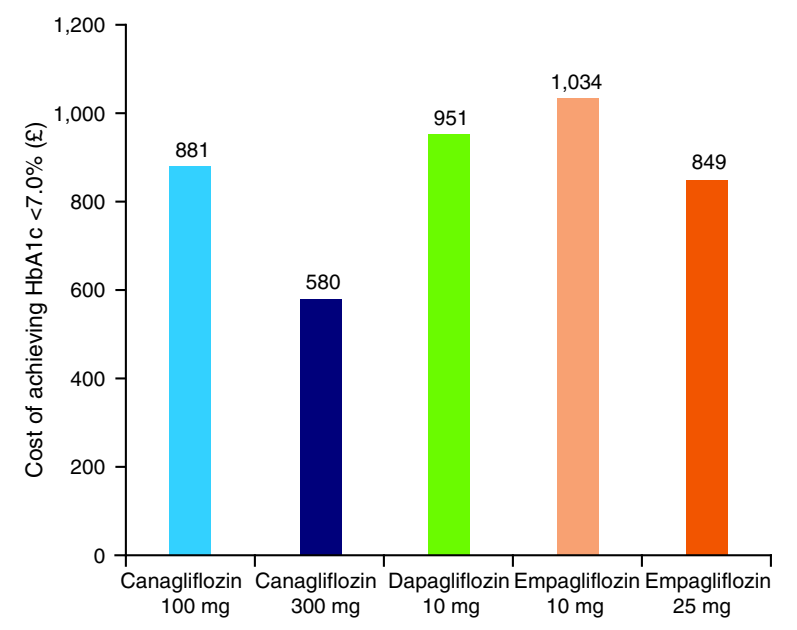

Fig. 4 Cost per patient of achieving HbAlc $<7.0 \%$ at 26 weeks

Ireland to $71.5 \%$ in Wales [26]. Additionally, there is a large degree of variation in both spending on diabetes and diabetes-related outcomes among Clinical Commissioning Groups, NHS bodies responsible for local planning and commissioning of healthcare services, within England [27]. Estimating the costs per response allows healthcare providers to make informed recommendations about treatment options that balance efficacy and cost and can reduce variations in care.

The recent Empagliflozin Cardiovascular Outcome Event Trial in Type 2 Diabetes Mellitus Patients (EMPA-REG OUTCOME) of empagliflozin and The Comparative Effectiveness of Cardiovascular Outcomes (CVD-REAL) realworld study of SGLT2 inhibitors found that SGLT2 inhibitor treatment provided cardiovascular $(\mathrm{CV})$ benefits in patients with T2DM and a history of CV disease [28, 29]. Similarly, the CANagliflozin cardioVascular Assessment Study (CANVAS) Program of canagliflozin in a broad population of patients with T2DM and a history or high risk of $\mathrm{CV}$ disease found a reduced risk of the primary composite major adverse $\mathrm{CV}$ events endpoint with canagliflozin compared with placebo (hazard ratio [95\% confidence interval]: $0.86[0.75,0.97]$ ) [30]. Thus, the emerging evidence suggests that CV benefits are likely to be a class effect of SGLT2 inhibitors and these potential benefits will be important to consider in future cost-effectiveness analyses.
Results from the ongoing Dapagliflozin Effect on CardiovascuLAR Events (DECLARE; NCT01730534) trial of dapagliflozin will provide further information on the $\mathrm{CV}$ benefits of SGLT2 inhibitors.

In addition to the potential benefits of SGLT2 inhibitor treatment, the safety profiles of these agents may impact their cost-effectiveness. Commonly reported adverse events include genital mycotic infections, transient polyuria with mild dehydration, and lower urinary tract infections [31]. Furthermore, a few safety signals have recently emerged that may also negatively impact the cost-effectiveness of SGLT2 inhibitors versus other AHAs. Rare cases of diabetic ketoacidosis (DKA), including life-threatening ones, have been reported in patients with T2DM treated with SGLT2 inhibitors [32]. In the clinical trials of canagliflozin, 12 patients experienced DKA, including 4 $(0.07 \%), 6(0.11 \%)$, and $2(0.03 \%)$ treated with canagliflozin 100 and $300 \mathrm{mg}$ and comparator, respectively; the majority of these patients were being treated with insulin, and six of the patients treated with canagliflozin had evidence of latent autoimmune diabetes or type 1 diabetes [33]. Rates of DKA were also low in the clinical trials of empagliflozin; a total of 11 patients experienced DKA, including $5(0.1 \%), 1$ $(<0.1 \%)$, and $5(0.1 \%)$ treated with empagliflozin 10 and $25 \mathrm{mg}$ and placebo, respectively [34]. Of note, no increase in the risk of DKA was observed in the CANVAS Program or EMPA-REG OUTCOME [28, 30].

Post-marketing data from the FDA Adverse Events Reporting System (FAERS) through the end of 2015 identified a potential safety signal for acute kidney injury with all three SGLT2 inhibitors [35]. Canagliflozin, dapagliflozin, and empagliflozin all carry warnings from the FDA about increased risk of acute kidney injury $[36,37]$. In contrast, no evidence of an increased risk of acute kidney injury was observed in the CANVAS Program or EMPA-REG OUTCOME [28, 30].

Emerging evidence suggests that SGLT2 inhibitors may be associated with an increased risk of lower-extremity amputation, the mechanism for which is unknown, but under investigation [38]. In the high CV risk population that 
comprised the CANVAS Program, an increased risk of amputation, mainly of the toe, was observed. Over the course of the CANVAS Program, amputation was uncommon, occurring at a rate of 6.3 and 3.4 per 1000 patient-years for patients treated with canagliflozin and placebo, respectively, which constitutes an increased risk of 1.97-fold; patients with a history of prior amputation, peripheral vascular disease, and neuropathy were at the highest risk [30]. To date, limited additional data are available on the risk of amputation with empagliflozin and dapagliflozin, so it is currently not possible to establish whether or not the increased risk of amputation is an SGLT2 inhibitor class effect [39]. To further evaluate this risk, the European Medicines Agency (EMA) has now mandated that lower-extremity amputations be systematically captured in studies of SGLT2 inhibitors [40]. Information on the risk of lower-limb amputation has been added to the canagliflozin EMA summary of product characteristics; however, risk factors, other than general risk factors for amputation, are not known since the underlying mechanism has not been identified [41]. As a precaution, it is recommended that patients at high risk for amputation events should be carefully monitored and counseled about the importance of routine preventative foot care and maintaining adequate hydration, and that consideration should be given to stopping treatment in patients who develop amputation-preceding events including lowerextremity skin ulcer, infection, osteomyelitis, and gangrene [41].

Across phase 3 trials, canagliflozin treatment was associated with an increased risk of adverse events related to the mechanism of SGLT2 inhibition (i.e., genital mycotic infections, osmotic diuresis-related adverse events), but was generally well tolerated with a low rate of discontinuation due to adverse events [42]. As with all therapies, it will be important from both a clinical and economic perspective to balance these potential risks with the possible benefits for patients.

This study was limited by the simplistic nature of the analysis. Simple cost per HbA1c response analyses do not factor in the impact of potential differences in side effects or other benefits (i.e., avoidance of hypoglycemia, improvements in weight and blood pressure, and the potential cardioprotective effects of SGLT2 inhibition). Future studies evaluating cost per patient achieving relevant composite endpoints could also provide potentially valuable economic data. Two recent studies took this approach and showed cost advantages with liraglutide compared with lixisenatide and older therapies for T2DM [43, 44]. Additionally, this type of analysis does not include a willingness-to-pay threshold per patient achieving their glycemic target, and comparisons across therapeutic areas are not possible, unlike conventional cost per QALY modeling. However, estimating the cost of achieving HbA1c targets remains valuable given the known impact of good glycemic control on reducing the risk of complications in patients with T2DM [9].

\section{CONCLUSION}

Overall, this analysis suggests that canagliflozin $300 \mathrm{mg}$ provides the best value for money among all SGLT2 inhibitors available in the UK in terms of achieving HbA1c $<7.0 \%$. The addition of canagliflozin to the treatment regimen of patients with T2DM who have inadequate glycemic control with metformin and sulfonylurea may provide significant cost savings by reducing diabetes-related complications.

\section{ACKNOWLEDGEMENTS}

Sponsorship for this study and article processing charges were funded by Janssen Global Services, LLC, Raritan, NJ, USA. Medical writing assistance was provided by Dana Tabor, $\mathrm{PhD}$, of MedErgy, and was funded by Janssen UK. All authors had full access to all of the data in this study and take complete responsibility for the integrity of the data and accuracy of the data analysis. All named authors meet the Institutional Committee of Medical Journal Editors (ICMJE) criteria for authorship for this manuscript, take responsibility for the integrity of the work as a whole, and have given final approval for the version to be published. 
Disclosures. Marc Evans has served as an advisory panel member and received speaker fees from Novo Nordisk, Sanofi-Aventis, Novartis, Merck Sharp \& Dohme, AstraZeneca, and Janssen. Sayeed Achha is a full-time employee of Janssen UK. Cheryl Neslusan is a full-time employee of Janssen Global Services, LLC.

Previous Presentations. This work has previously been presented, in part, at the International Society for Pharmacoeconomics and Outcomes Research (ISPOR) 18th Annual European Congress on November 7-11, 2015 in Milan, Italy and the International Society for Pharmacoeconomics and Outcomes Research (ISPOR) 19th Annual European Congress on October 29-November 2, 2016 in Vienna, Austria.

Compliance with Ethics Guidelines. This article is based on previously conducted studies and does not involve any new studies of human or animal subjects performed by any of the authors.

Data Availability. The datasets generated and/or analyzed during the current study are available from the corresponding author on reasonable request.

Open Access. This article is distributed under the terms of the Creative Commons Attribution-NonCommercial 4.0 International License (http://creativecommons.org/licenses/ by-nc/4.0/), which permits any non commercial use, distribution, and reproduction in any medium, provided you give appropriate credit to the original author(s) and the source, provide a link to the Creative Commons license, and indicate if changes were made.

\section{REFERENCES}

1. Hex N, Bartlett C, Wright D, Taylor M, Varley D. Estimating the current and future costs of Type 1 and Type 2 diabetes in the UK, including direct health costs and indirect societal and productivity costs. Diabet Med. 2012;29:855-62.
2. Diabetes UK. Facts and stats. 2016. https://www. diabetes.org.uk/Professionals/Position-statementsreports/Statistics/. Accessed 1 May 2017.

3. Health and Social Care Information Centre. Prescribing for diabetes: England 2005-06 to 2013-14. $2014 . \quad$ http://content.digital.nhs.uk/catalogue/ PUB14681/pres-diab-eng-200506-201314-rep.pdf. Accessed 16 Nov 2016.

4. NHS England. Five Year Forward View. 2014. https://www.england.nhs.uk/wp-content/uploads/ 2014/10/5yfv-web.pdf. Accessed 3 May 2017.

5. Berwick DM, Nolan TW, Whittington J. The triple aim: care, health, and cost. Health Aff (Millwood). 2008;27:759-69.

6. Cripps M. NHS right care-expanding the approach in the context of delivering the Five Year Forward View. Paper 5. 2015. https://www.england.nhs.uk/wpcontent/uploads/2015/12/nqb-oct15-5.pdf. Accessed 8 May 2017.

7. National Institute for Health and Care Excellence. Type 2 diabetes in adults: management. Clinical guideline update (NG28) methods, evidence and recommendations. 2015. https://www.nice.org.uk/ guidance/ng28. Accessed 16 Nov 2016.

8. Gilmer TP, O'Connor PJ, Manning WG, Rush WA. The cost to health plans of poor glycemic control. Diabetes Care. 1997;20:1847-53.

9. UK Prospective Diabetes Study (UKPDS) Group. Intensive blood-glucose control with sulphonylureas or insulin compared with conventional treatment and risk of complications in patients with type 2 diabetes (UKPDS 33). Lancet. 1998;352:837-53.

10. Health and Social Care Information Centre. National diabetes audit 2013-2014 and 2014-2015, report 1: care processes and treatment targets. 2016. http:// www.hscic.gov.uk/catalogue/PUB19900/nati-diabrep1-audi-2013-15.pdf.

11. Abdul-Ghani MA, Norton L, DeFronzo RA. Renal sodium-glucose cotransporter inhibition in the management of type 2 diabetes mellitus. Am J Physiol Renal Physiol. 2015;309:F889-900.

12. Mudaliar S, Polidori D, Zambrowicz B, Henry RR. Sodium-glucose cotransporter inhibitors: effects on renal and intestinal glucose transport: from bench to bedside. Diabetes Care. 2015;38:2344-53.

13. Wilding JP, Charpentier G, Hollander P, et al. Efficacy and safety of canagliflozin in patients with type 2 diabetes mellitus inadequately controlled with metformin and sulphonylurea: a randomised trial. Int J Clin Pract. 2013;67:1267-82. 
14. Schernthaner G, Gross JL, Rosenstock J, et al. Canagliflozin compared with sitagliptin for patients with type 2 diabetes who do not have adequate glycemic control with metformin plus sulfonylurea: a 52-week, randomized trial. Diabetes Care. 2013;36:2508-15.

15. Matthaei S, Bowering K, Rohwedder K, Grohl A, Parikh S. Dapagliflozin improves glycemic control and reduces body weight as add-on therapy to metformin plus sulfonylurea: a 24-week randomized, double-blind clinical trial. Diabetes Care. 2015;38:365-72.

16. Häring HU, Merker L, Seewaldt-Becker E, et al. Empagliflozin as add-on to metformin plus sulfonylurea in patients with type 2 diabetes: a 24-week, randomized, double-blind, placebo-controlled trial. Diabetes Care. 2013;36:3396-404.

17. Matthaei S, Bowering K, Rohwedder K, Sugg J, Parikh S, Johnsson E. Durability and tolerability of dapagliflozin over 52 weeks as add-on to metformin and sulphonylurea in type 2 diabetes. Diabetes Obes Metab. 2015;17:1075-84.

18. Häring HU, Merker L, Christiansen $A V$, et al. Empagliflozin as add-on to metformin plus sulphonylurea in patients with type 2 diabetes. Diabetes Res Clin Pract. 2015;110:82-90.

19. Zaccardi F, Webb DR, Htike ZZ, Youssef D, Khunti $\mathrm{K}$, Davies MJ. Efficacy and safety of sodium-glucose cotransporter 2 inhibitors in type 2 diabetes mellitus: systematic review and network meta-analysis. Diabetes Obes Metab. 2016;18:783-94.

20. Shyangdan DS, Uthman OA, Waugh N. SGLT-2 receptor inhibitors for treating patients with type 2 diabetes mellitus: a systematic review and network meta-analysis. BMJ Open. 2016;6:e009417.

21. Taieb V, Pacou M, Schroeder M, Schubert A, Nielsen A. Network meta-analysis to assess relative efficacy measured as percentage of patients treated to HbA1c target with canagliflozin in patients with type 2 diabetes mellitus inadequately controlled on metformin and sulphonylurea. Poster presented at: International Society for Pharmacoeconomics and Outcomes Research (ISPOR) 18th Annual European Congress; November 7-11 2015; Milan, Italy.

22. Dias S, Sutton AJ, Ades AE, Welton NJ. Evidence synthesis for decision making 2: a generalized linear modeling framework for pairwise and network meta-analysis of randomized controlled trials. Med Decis Making. 2013;33:607-17.

23. National Institute for Health and Care Excellence (NICE). NICE guide to the methods of technology appraisal. 2013. https://www.nice.org.uk/process/ pmg9/resources/guide-to-the-methods-of-technology -appraisal-2013-pdf-2007975843781. Accessed 16 Nov 2016.
24. Spiegelhalter DJ, Best NG, Carlin BP, van der Linde A. Bayesian measures of model complexity and fit. J R Stat Soc B. 2002;64:583-639.

25. Lopez JM, Macomson B, Ektare V, Patel D, Botteman M. Evaluating drug cost per response with SGLT2 inhibitors in patients with type 2 diabetes mellitus. Am Health Drug Benefits. 2015;8:309-18.

26. Jamie G. DM007: UK-QOF database. 2016. https:// www.gpcontract.co.uk/child/UK/DM007/16. Accessed 8 May 2017.

27. Cripps $M$, Brambleby $\mathrm{P}$, Lawson A. Paul Adams scenario. The story of Paul's experience of a diabetes care pathway, and how it could be so much better. Rights Care Casebook Series 2014. https:// www.england.nhs.uk/rightcare/wp-content/uploads/ sites/40/2016/09/Casebook_Paul-Adams-Scenario_ Diabetes.pdf. Accessed 8 May 2017.

28. Zinman B, Wanner C, Lachin JM, et al. Empagliflozin, cardiovascular outcomes, and mortality in type 2 diabetes. N Engl J Med. 2015;373:2117-28.

29. Kosiborod M, Cavender MA, Fu AZ, et al. Lower risk of heart failure and death in patients initiated on SGLT-2 inhibitors versus other glucose-lowering drugs: the CVD-REAL Study. Circulation. 2017;136:249-59.

30. Neal B, Perkovic V, Mahaffey KW, et al. Canagliflozin and cardiovascular and renal events in type 2 diabetes. N Engl J Med. 2017;377:644-57.

31. Trujillo JM, Nuffer WA. Impact of sodium-glucose cotransporter 2 inhibitors on nonglycemic outcomes in patients with type 2 diabetes. Pharmacotherapy. 2017;37:481-91.

32. European Medicines Agency. EMA confirms recommendations to minimise ketoacidosis risk with SGLT2 inhibitors for diabetes. Healthcare professionals should be aware of possible atypical cases. 2016. http://www.ema.europa.eu/docs/en_GB/document library/Referrals_document/SGLT2_inhibitors_20/ European_Commission_final_decision/WC500202 393.pdf. Accessed 5 May 2017.

33. Erondu N, Desai M, Ways K, Meininger G. Diabetic ketoacidosis and related events in the canagliflozin type 2 diabetes clinical program. Diabetes Care. 2015;38:1680-6.

34. Kohler S, Zeller C, Iliev H, Kaspers S. Safety and tolerability of empagliflozin in patients with type 2 diabetes: pooled analysis of phase I-III clinical trials. Adv Ther. 2017;34(7):1707-26.

35. Desai M, Yavin Y, Balis D, et al. Renal safety of canagliflozin, a sodium glucose co-transporter 2 inhibitor, in patients with type 2 diabetes mellitus. Diabetes Obes Metab. 2017;19(6):897-900. 
36. US Food and Drug Administration. FDA drug safety communication: FDA strengthens kidney warnings for diabetes medicines canagliflozin (Invokana, Invokamet) and dapagliflozin (Farxiga, Xigduo XR). 2016. http://www.fda.gov/Drugs/DrugSafety/ ucm505860.htm. Accessed 16 Nov 2016.

37. JARDIANCE ${ }^{\circledR}$ (empagliflozin) tablets, for oral use [package insert]. Ridgefield: Boehringer Ingelheim Pharmaceuticals; 2016.

38. European Medicines Agency. SGLT2 inhibitors: information on potential risk of toe amputation to be included in prescribing information. 2017. http://www.ema.europa.eu/docs/en_GB/document_ library/Press_release/2017/02/WC500222191.pdf. Accessed 26 May 2017.

39. European Medicines Agency. PRAC concludes that diabetes medicine canagliflozin may contribute to risk of toe amputation. Risk may also apply to other medicines in the same class. 2017. http://www.ema.europa.eu/docs/en_GB/document_ library/Referrals_document/SGLT2_inhibitors_Canagliflozin_20/Recommendation_provided_by_Pharmacovigilance_Risk_Assessment_Committee/WC5 00221431.pdf. Accessed 27 Jun 2017.

40. European Medicines Agency. PRAC assessment report. 2017. http://www.ema.europa.eu/docs/en_ GB/document_library/Referrals_document/SGLT2_ inhibitors_Canagliflozin_20/European_Commission_ final_decision/WC500227102.pdf. Accessed 16 Jun 2017.

41. Invokana (300 mg film-coated tablets), [package insert]. Beerse: Janssen-Cilag International NV; 2017.

42. Rosenthal N, Meininger G, Ways K, et al. Canagliflozin: a sodium glucose co-transporter 2 inhibitor for the treatment of type 2 diabetes mellitus. Ann NY Acad Sci. 2015;1358:28-43.

43. Hunt B, McConnachie CC, Gamble C, Dang-Tan T. Evaluating the short-term cost-effectiveness of liraglutide versus lixisenatide in patients with type 2 diabetes in the United States. J Med Econ. 2017;11:1-4.

44. Skovgaard R, Jon Ploug U, Hunt B, Valentine WJ. Evaluating the cost of bringing people with type 2 diabetes mellitus to multiple targets of treatment in Canada. Clin Ther. 2015;37:1677-88.

45. Russell-Jones D, Vaag A, Schmitz O, et al. Liraglutide vs insulin glargine and placebo in combination with metformin and sulfonylurea therapy in type 2 diabetes mellitus (LEAD-5 met $+\mathrm{SU}$ ): a randomised controlled trial. Diabetologia. 2009;52:2046-55.

46. Hermansen K, Kipnes M, Luo E, Fanurik D, Khatami H, Stein P. Efficacy and safety of the dipeptidyl peptidase- 4 inhibitor, sitagliptin, in patients with type 2 diabetes mellitus inadequately controlled on glimepiride alone or on glimepiride and metformin. Diabetes Obes Metab. 2007;9:733-45.

47. Heine RJ, Van Gaal LF, Johns D, Mihm MJ, Widel $\mathrm{MH}$, Brodows RG. Exenatide versus insulin glargine in patients with suboptimally controlled type 2 diabetes: a randomized trial. Ann Intern Med. 2005;143:559-69.

48. Kendall DM, Riddle MC, Rosenstock J, et al. Effects of exenatide (exendin-4) on glycemic control over 30 weeks in patients with type 2 diabetes treated with metformin and a sulfonylurea. Diabetes Care. 2005;28:1083-91.

49. Liu SC, Chien KL, Wang $\mathrm{CH}$, Chen WC, Leung $\mathrm{CH}$. Efficacy and safety of adding pioglitazone or sitagliptin to patients with type 2 diabetes insufficiently controlled with metformin and a sulfonylurea. Endocr Pract. 2013;19:980-8.

50. Lukashevich V, Del Prato S, Araga M, Kothny W. Efficacy and safety of vildagliptin in patients with type 2 diabetes mellitus inadequately controlled with dual combination of metformin and sulphonylurea. Diabetes Obes Metab. 2014;16:403-9.

51. Owens DR, Swallow R, Dugi KA, Woerle HJ. Efficacy and safety of linagliptin in persons with type 2 diabetes inadequately controlled by a combination of metformin and sulphonylurea: a 24-week randomized study. Diabet Med. 2011;28:1352-61.

52. Bergenstal R, Lewin A, Bailey T, et al. Efficacy and safety of biphasic insulin aspart 70/30 versus exenatide in subjects with type 2 diabetes failing to achieve glycemic control with metformin and a sulfonylurea. Curr Med Res Opin. 2009;25:65-75.

53. Strojek K, Bebakar WM, Khutsoane DT, et al. Once-daily initiation with biphasic insulin aspart 30 versus insulin glargine in patients with type 2 diabetes inadequately controlled with oral drugs: an open-label, multinational RCT. Curr Med Res Opin. 2009;25:2887-94.

54. Yang W, Xu X, Liu X, et al. Treat-to-target comparison between once daily biphasic insulin aspart 30 and insulin glargine in Chinese and Japanese insulin-naive subjects with type 2 diabetes. Curr Med Res Opin. 2013;29:1599-608.

55. Hartemann-Heurtier A, Halbron M, Golmard JL, et al. Effects of bed-time insulin versus pioglitazone on abdominal fat accumulation, inflammation and gene expression in adipose tissue in patients with type 2 diabetes. Diabetes Res Clin Pract. 2009;86:37-43. 